\title{
Synergies between an Observed Port and a Logistic Company: Application of the Discounted Cash-Flow Model and the Monte Carlo Simulation
}

\author{
Dejan DRAGAN1, Boja n ROSI ${ }^{1}$ and Toni AVŽNER ${ }^{1}$ \\ ${ }^{1}$ University of Ma ribor/Fa c ulty of Log istic s, Celje, Slovenia
}

\begin{abstract}
The paper addresses an analysis of potential synergies in collaboration between an observed Port in the Meditemanean Sea and Central-European logistic railway-senices based company. Both companies have established a strategic partnership. The main motive was cooperation in rail transport, with a particular emphasis on potential synergies that would a rail traffic have brought to a port's business. For the purpose of synergies valuation under uncertain conditions, a Monte Carlo simulation-based framework with integrated discounted cash flow (DCF) model is applied. The possible values of future synergies are calculated via the DCF model by simultaneously changing values of different uncertain financial parameters at each repetition of a Monte Carlo scenario-playing mechanism. In this process, predicted forecasts of future synergetic throughputs are also used for various types of obsenved cargo. As it tumed out, the generated synergies' values follow the approximate nomal distribution. Based on statistical inference and analysis of probability intervals it was discovered that there might indeed exist certain important synergies in the collaboration between both companies. This fact has convinced us into a belief in the comectness of companies' decision to enter into such kind of strategic cooperation.
\end{abstract}

Key words - Port Economics, Financial Management and Valuation, Synergies, Logistics, Companies' Collaboration, Discounted Cash-Fow Model, Monte Carlo Simulation.

\section{INTRODUCTION}

Nowadays, companies can collaborate in many different strategic alliances, such as joint ventures, equity investments, cooperatives, $R \& D$ consortia, cartels, strategic cooperative agreements, and so on [1]. In general, strategic alliances are partnerships in which two or more fims cooperate together to attain goals that are mutually beneficial [2]. Fims may share information, resources, capabilities and risks to achieve shared objectives. A common motivation for incoming into a strategic alliance is to take an advantage of a nother fim's innovations without having to finance in new research and development[2]. The business literature has already recognized a number of positive effects for fims actively involved in strategic alliances, such as better retum on investment, higher retum on equity, and higher success rates. These are important advantages that place the strategic alliances in a dominant position in comparison with classical mergers and acquisitions [1]. A stra tegic alliance engages at least two partner companies that: 1. continue to be legally independent after the formation of alliance; 2 . share welfares and management control over the operating performance; 3 . camy on continuing contributions in at least one strategic areas, such as technology or products [1].

Strategic alliances are also important for firms that are involved in any sort of supply cha in (SC) cooperation. Consciousness about a strategic significance of collaboration between suppliers, manufacturers, and customers, is still rising [3]. Many studies have shown that the supply chain cooperation can improve the fims' performance. By working in partnership with supply chain members, companies a re expected to multiply the results of their shared efforts. Such results can comprise an increased level of responsiveness and progression of service levels from their shared collaborative programs [3].

Among other motives, achieved synergies are one of the major reasons for SC companies to enter into the strategic alliance. There are several definitions of synergy between two or more companies. As Benecke and his colleagues [4] point out, the synergy can be defined as the 
collaboration of two or more intellectual capital resources, which improves the combined outcome of value creation and competitive performance, where the effect is better than the sum of the individual effects [4]. Synergy can also be defined as the concept where the combination of two or more different activities, businesses, or processes will generate an overall value that is bigger than the sum of the individual parts [4]. Moreover, the concept of synergy implies that advantages are formed when economies of scale and speed are combined with administrative coordination [4].

This paper represents the results of analysis of potential synergies in a strategic collaboration between an observed port in Slovenia (the Port of Koper) and an intemational logistic company (LC), which provides railway servic es as its primary activity. The port is located in the Adriatic Sea (part of the Mediterranean Sea), while the logistic company has its chair in Slovakia and covers the Central and East-European area. The main motive for the strategic alliance was cooperation on grounds of mutual benefits related to a rail freight transport. Here, the potential synergies that would rail traffic have brought to a port's businesses have played one of the main reasons for the alliance.

Namely, the logistic company is a strong intemational player and is, in fact, present in markets which are of interest to the port as well. Accordingly, it was expected that a synchronized optimal coordination of activities of both companies would also inc rease the cargo throughput volume in the port. Such kind of sumlus in cargo amount (synergetic based extra cargo throughput) is ma inly supposed to be a consequence of synergetic effects that would arise in the strategic collaboration between both companies. On this grounds, it was also expected that an additional synergetic throughput might positively contribute in amplifying a role of the observed port to become one of the leading port and service systems for providing goods to the Central-and East European countries. Based on this strategy, the port would also have got a chance to more efficiently manage the links in the supply chain.

In this paper, the possibly achieved synergies (synergetic values) are measured in mio EUR and can be treated as an estimated total present value of future cash flows based on these synergies for a certain time period (e.g. five years). The synergetic values are based on the ex-ante estimated extra cargo synergetic throughput measured in TEUs (conta iners) or k-tones (other types of cargo).

For the purpose of synergies valuation, a disc ounted cash flow (DCF) model $[5,6]$ integrated into the Monte Carlo (MC) simulation-based framework is applied [7-16]. The DCF model links the value of an asset (synergetic revenue in our case) to the present value (PV)of expected future cash flows on that a sset $[17,18]$. It conta ins several uncerta in fina ncial pa ra meters that a re treated as random variables, which follow a specific predefined probability distribution. At each repetition of MC algorithm, the financial pa ra meters change their values according to their probability distributions. This way, a different static (point) estimates for synergies' future values are calculated at each simulation. By repeating the described process, MC iterations are executed for many (thousands) times, which gives us an enomous number of generated synergies' values. As it tums out, these values follow an approximately nomal distribution. Moreover, not only the total synergies' values follow a nomal distribution, but also partial synergies for different cargo types have this kind of distribution as well.

The DCF model obtained for each cargo type also needs a predicted future cargos' synergetic throughput as one of its inputs. The latter represents a forec asted throughput's sumplus based on the achieved synergies and was acquired by the means of the port's ERP/SAP system. When the MC algorithm is totally completed, statistical inference and analysis of probability intervals from calculated histograms might also become possible. The statistical a nalysis shows that there indeed exists a high probability of a ppea rance of significant future synergetic values for all cargo types of the observed port. More importantly, due to an estimated high probability of the existence of substantial total future synergies (sum of partial synergies of individual cargo types), this fact should be an important indicator for every responsible organization to enter into such collaboration with the partner company.

Accordingly, our findings result in the important conclusion that the judgment about establishing a strategic partnership between both companies was an appropriate and useful decision of port's management. Besides the practical implications of our results, we believe that the following additional contributions have been achieved in this paper: 1 . It is clearly shown how the MonteCarlo approach and DCF model can be combined to calculate synergies related to the throughputs in ports; 2 . there have been practically no papers detected in the literature that would estimate a future value of throughputs' based synergies in a way as we did in our paper; 3. Conversely to a majority of synergy-based studies, which focus only on mergers \& acquisitions 
$(M \& A)$, our study analyzed a strategic alliance of two companies involved in the supply chain distribution framework.

Statistical implic ations of our study can be summarized as follows. It is shown that a probability of achieving high future synergetic effects, watched from the ex-ante perspective of historical time, can reach a signific ant value from the set of all possible realizations (outcomes). From this can be deduced that the port's decision about a strategic partnership with a logistic company was the correct decision.

\section{LTTERATURE REVIEW}

\section{A. Synergies in a supply chain collaboration}

During the last few decades, scholars introduced several different classifications of business synergies (see Fig. 1). Ansoff in his work [19] introduced one of the first classifications when he defined the different forms of synergies as: sales synergy, operating synergy, investment synergy and management synergy [20]. Here, sales synergy referred to increased revenue, operating synergy referred to decreased operating cost, while investment synergy referred to decreased investment requirements. Two decades later, Chatteriee [21] termed the various types of synergies as: collusive synergy, operational synergy and financial synergy [20]. In this context, the first two types of synergies referred to a concept very close to the characterizations used by Ansoff for sales and operating synergy, respectively. However, according to Chatterjee, financial synergy arises from a reduction in the cost of capital [20]. Later, McKinsey \& Company, in their in-depth guide to valuations (2005), has differentiated between only two types of synergy: cost synergies and revenue synergies [22].

Copeland and Weston [17] had provided a more strict definition of synergy when they suggested that synergy exists when the net present value (NPV) of the cash flow of the combination of two assets is greater than the sum of the NPVs of the cash flows of the assets independently. Eccles and his colleagues [23] identified five types of synergies, which correspond to: 1. Cost savings; 2. Process improvements; 3. More effic ient financial engineening; 4. Tax benefits; and 5. Revenue enhancements [20]. As it tums out, it is quite diffic ult to create a cross-link between various classifications of the synergies provided by the diverse scholars. Maybe the best crosslinkage was made by de Graaf in his work [20] (see Table 1).
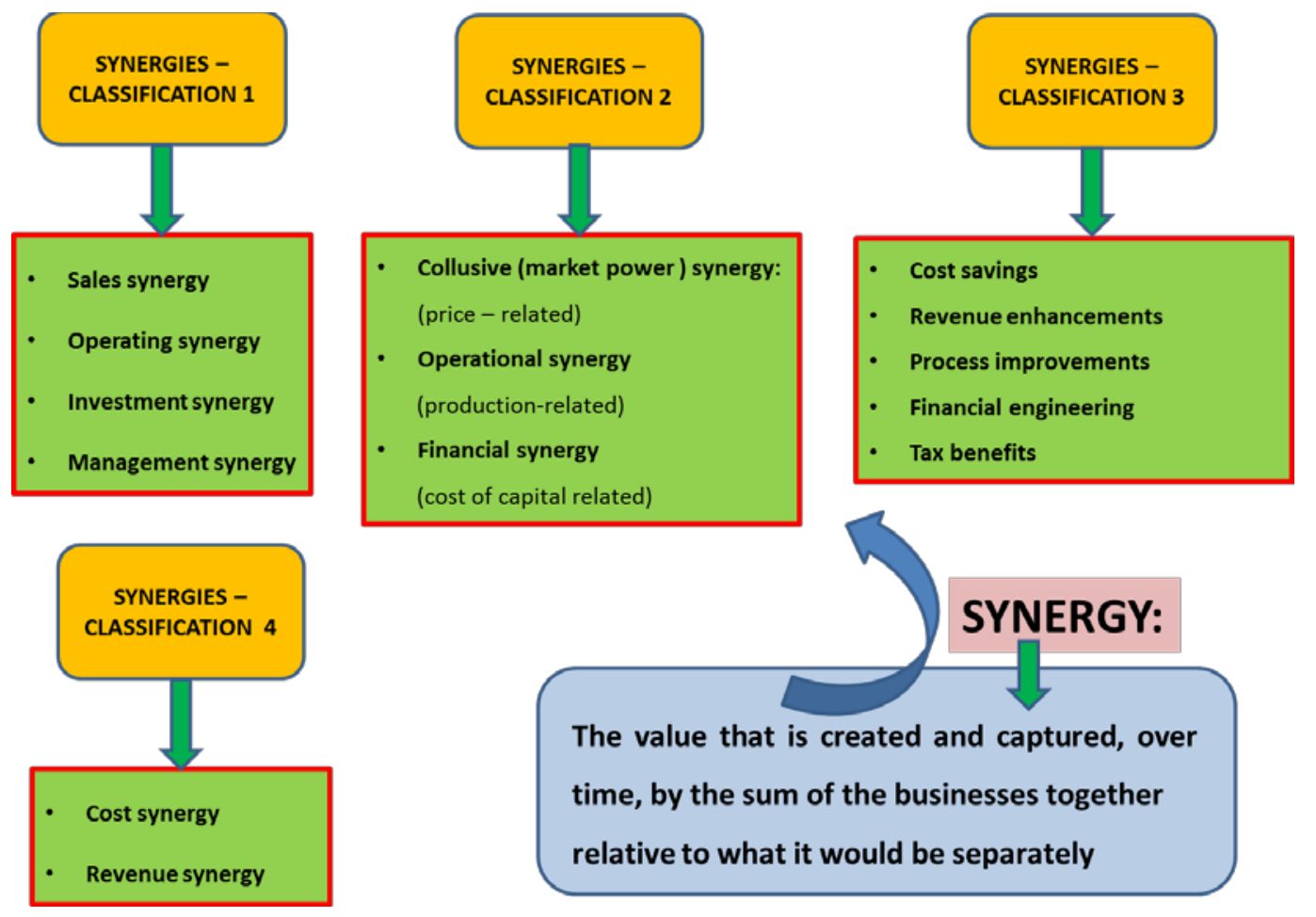

Fig ure 1. Different c la ssific a tions of business synergies. 
Table 1 . The cross-linka ge between various c lassific ations of the synergies provided by the diverse scholars.

\begin{tabular}{|c|c|c|c|}
\hline & & \multicolumn{2}{|c|}{ Mc Kinsey \& Company (2005) } \\
\hline & & Cost synergies & Revenue synergies \\
\hline Ansoff (1965) & $\begin{array}{l}\text { Sales synergy } \\
\text { Operating synergy } \\
\text { Investment synergy }\end{array}$ & $\begin{array}{l}\checkmark \\
\checkmark\end{array}$ & $\checkmark$ \\
\hline Chaterjee (1986) & $\begin{array}{l}\text { Collusive synergy } \\
\text { Operational synergy } \\
\text { Financial synergy }\end{array}$ & $\begin{array}{l}\checkmark \\
\checkmark\end{array}$ & d \\
\hline Eccleset al. (1999) & $\begin{array}{l}\text { Cost savings } \\
\text { Revenue enhancements } \\
\text { Process improvements } \\
\text { Financial engineering } \\
\text { Tax benefits }\end{array}$ & $\begin{array}{l}2 \\
2 \\
2 \\
2 \\
2\end{array}$ & $\checkmark$ \\
\hline
\end{tabular}

The effect of comorate synergy has been investigated in many works, mainly focused on companies involved in $M \& A[6,22,24-28]$. On the other side, there have been an essentially lower number of studies introduced addressing the synergies within the supply chains, particularly those present in the vertical direction. However, synergetic effects can be even more important for the members vertically distributed along the SC. The main origin of such synergies arises from coord inated operational functioning and decision-making, as well as from optimal co-ordination of activities along the supply chain. As [29] emphasizes, strategic alliances can be a much more effic ient way to increase the performance of the companies involved in the SC than is the case of acquisitions or mergers. According to [29], the main reason is globalization, which forces companies to establish strategic partnerships. Such partnerships can through outsourc ing, effective information sharing (the importance of the Intemet!), a joint appearance on the market and the risk-sharing, joint research and development, and joint use of infrastructure and other resources/capacity, a chieve more effective operations management of involved companies [29].

The positive effects of synergies in the integration between the companies in the logistics profession both in the horizontal as well as in the vertical direction are precisely presented in the paper [30]. In most cases, the main motive for the strategic alliance is to achieve synergies arising from coordinated action and integration related, respectively. Such cooperation is especially important in cases where access to the markets of one enterprise opens the way to these markets also a nother company. Thus, this kind of networking companies in the logistic chain also positively impact on achieving higher operational and commercial synergies, as well as management synergies [30]. Accordingly, such collaboration is then reflected in better coordination of joint operational ac tivities, total exploitable resources and/or infra struc ture adapted to business in terms of providing optimal distribution channels.

\section{B. Valuations on assets and Disc ounted cash-flow model}

According to Damodaran [31], in finance are, in general terms, three approaches to valuation. The first one, discounted cash flow valuation, links the value of an asset to the present value of expected future cash flows on that asset. The second approach, relative valuation (valuation using multiples), estimates the asset's value by observing at the pric ing of 'comparable' assets relative to a common variable such as cash flows, eamings, book value or sales. Typical examples of relative valuation are for instance [18, 32]: enterprise value/net sales; enterprise value/operating free cash flow; enterprise value/invested capital, and other. The third approach to valuation, contingent claim valuation, applies option pricing models to measure the value of those assets that share options characteristic s [31].

Despite most valuations conducted in the real world are relative valuations, DCF valuation is the foundation on which all other valuation approaches are based. To do any relative valuation appropriately, we have to understand the basics of DCF valuation at first. Similarly, to employ option pricing models to value assets, we usually have to begin with a DCF valuation as well [31].

Disc ounted cash flow a nalysis represents a method of valuing a project, company, investment, or any other resource, including potential synergies $[6,17,33]$. To do so, this method uses a concept of the time value of money. Here, all future cash flows are estimated and discounted by 
using the cost of capital to obtain their present values [17, 34]. The sum of all future cash flows (incoming and outgoing) represents the net present value, which is treated as the value or price of the cash flows in question. Hence, the DCF analysis takes future cash flows and an appropriate disc ount rate as input on one side and gives an NPV value of the asset a s output on the other side.

The most commonly used method of discounting is exponential discounting, which values future cash flows in the sense of "how much money should be invested presently, at a given rate of retum, to produce the cash flow in the future." [35]. The discount rate applied is usually the suitable weighted average cost of capital (WACC), which reflects the risk of the cash flows. The disc ount rate mirrors two important things: 1 . Time value of money reflected via risk-free rate (investors would rather have cash instantly than waiting for it and must consequently be compensated by paying for time delay; 2 . Risk premium, which reflects the extra retum investors require because they want to be rewarded for the risk that a cash flow might not be materia lized et all [35].

\section{Valuations of synergies with the DCF model and Monte Carlo simulation}

Evans and Bishop [36] in their work recommend that the size of the synergy benefits should be quantified by using a DCF framework, engaging a conservative approach by incorporating a rigorous inquiring of such benefits [20]. These authors also recommend that a DCF model should include estima tes of expenditure, income, tax cost and financing, as well as cash investments in the working capital and non-c urrent assets. As emphasized in [36], the timing of synergy benefits is a lso essential and should be related to the period in which the various estimated cash flows are included. Moreover, the (ex-ante) projected timetable should be followed to achieve the (ex-post) synergy value.

The likelihood of success should also be incorporated in the estimated cash flows or the chosen discount rate. To do so, one way is to calculate the probability of different outcomes such as "optimistic", "expected" and "pessimistic". However, as Evans and Bishop emphasize, a better option is to perform a Monte Carlo simulation to estimate the likelihood of the success of future synergy effects [20]. Another method that considers the likelihood of success in the context of business decisions would be an applic ation of the real-options approach.

Monte Carlo simulations have been used successfully in the field of finance [20]. Hertz [37] was the first, who described the use of MC simulations in the making of capital investment decisions. He described a Monte Carlo simulation as a favored method applied to make a capital investment decision that is subject to numerous uncertainties since this method addresses all variables simultaneously. As [20] claims, there are many parallels between the uncerta inties faced in making a capital investment decision and quantifying values of certain types of synergies. Moreover, since the MC simulations might deliver some complexity, their use should be reserved for only those synergy calc ula tions that incorpora te many sourc es of unc erta inty [20].

Monte Carlo simulations are based on assigning random generators to all variables, for which the uncertainty must be incorporated. These generators have certa in probability distributions, settled theoretic ally or empiric ally. When the MC algorithm is running, the random generators take, according to their distributions, certa in values at each single MC iteration. This way, they conduct a randomness into corresponding variables. When the $M C$ algorithm is finished, the va riables conta in entire sets of generated random values, which can be further statistically analyzed via an observation of created histograms.

\section{STRATEGIC PLANNING AND FORECASTING OF SYNERGY THROUGHPUTS}

Fig. 2 shows relations that reflect ideas behind a strategic planning of the port to establish an alliance with a logistic company. The partnership would bring a cooperation and collaboration at different levels of coordinated decision-making, particularly in the scope of operations management. It is supposed that synchronized actions along the supply chain and better control of the operations would cause synergetic effects that will positively influence the better joint performance of both companies. This fact not only would raise the level of throughput of goods transported to Central-European countries via railway services of the logistic company but also would probably increase the attractiveness of the joint service of both companies. As a consequence, this might also positively impact on the decision of shippers providing goods from Far-East that would redirect their routes to the Mediterranean Sea instead of going via northem routes. On the long terms, such redirection is expected to contribute additionally to even bigger synergetic throughputs based on an efficient collaboration of both parties involved. 


\section{Logistic \& \& Susta ina ble Tra nsp ort \\ Vol. 8, No. 1, May 2017, 1-18 \\ doi: 10.1515/jlst-2017-0001}

Fig. 3 shows estimated forecasts of predic ted future synergetic throughputs for five major cargo types, denoted by: $\hat{y}_{i t}=\hat{y}_{i}(t), i=1,2,3,4,5$. Further deta ils and their characteristic s are not provided here since they are classified and not allowed to be publically revealed. It can be only revealed that the forecasted synergetic cargo throughputs (e.g. for the year 2012) from Fig. 3 represent 4.6\% - 20.1\% (it depends on the cargo type) of the actually a chieved mea sured total cargo throughputs in the year 2012. A more or less similar percentage range has been achieved for the other forecasted years (2008-2011) as well. Here, by total throughputs we refer to those throughputs generated by some other sources plus those generated by the achieved synergies. The forecasts in Fig. 3 were obtained by the means of the port's ERP/SAP system ${ }^{1}$ [38], which has also considered a well-planned future joint operations and strategies based on the effective collaboration between the both companies. Moreover, forecasts were carefully verified by the port's experts as well.

The increase in the future throughputs based on the achieved synergies would also positively influence on the bigger future revenues that correspond to a throughputs' rises in question. If these future synergetic based revenues are then considered within the scope of estimated future cash flows, they can accordingly be used in the DCF model for a further valuation of synergies. From Fig. 3 is also evident that the future planning horizon was ex-ante settled from the year 2008 to the year 2012: $t \in\{2008, \ldots, 2012\}$.

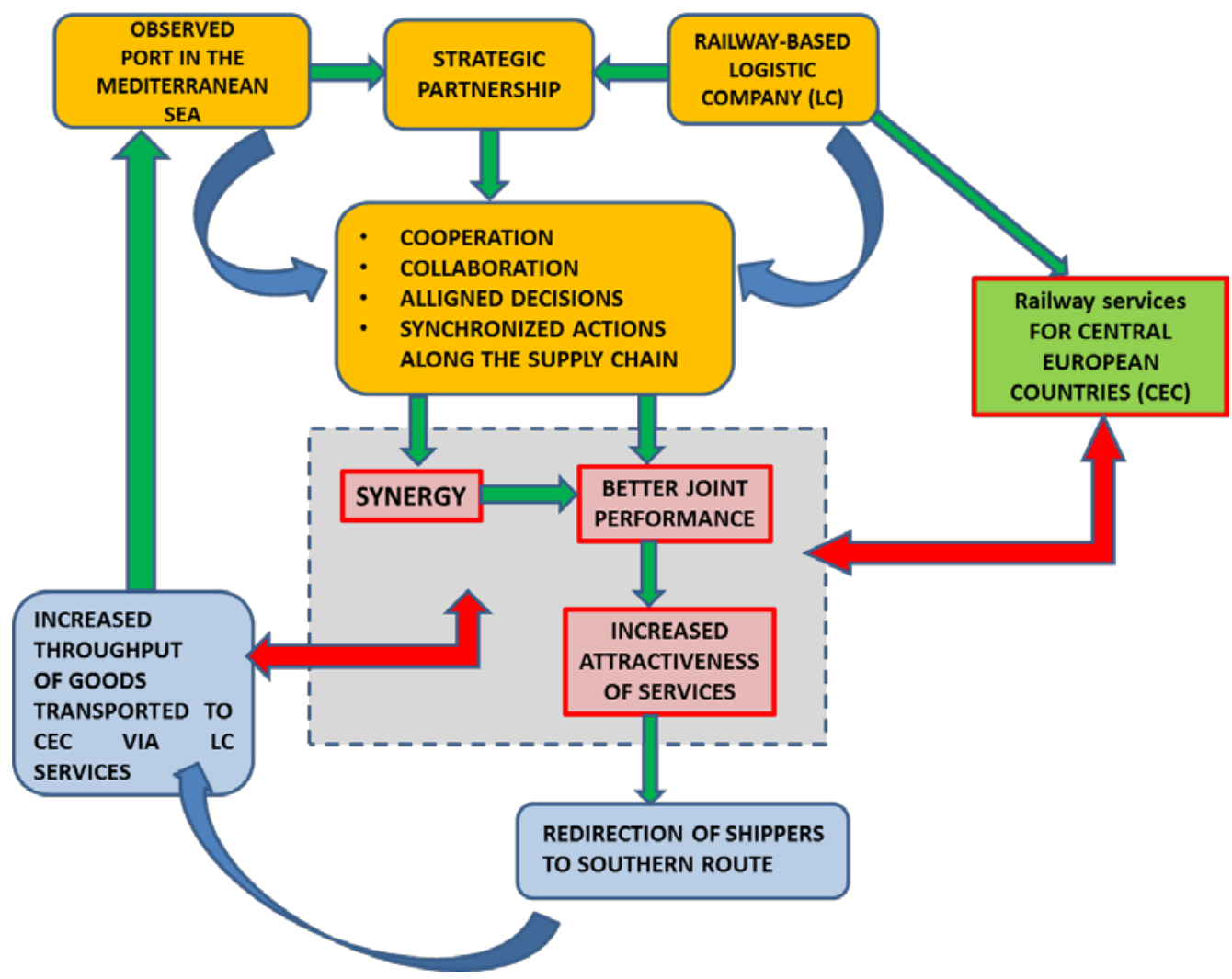

Figure 2. Relations that reflect ideas behind a strategic planning of the port to establish a n alliance with a logistic company.

\footnotetext{
${ }^{1}$ SAP: Systems, Applications \& Products in Data Processing; ERP: Enterprise resource planning business management software.
} 


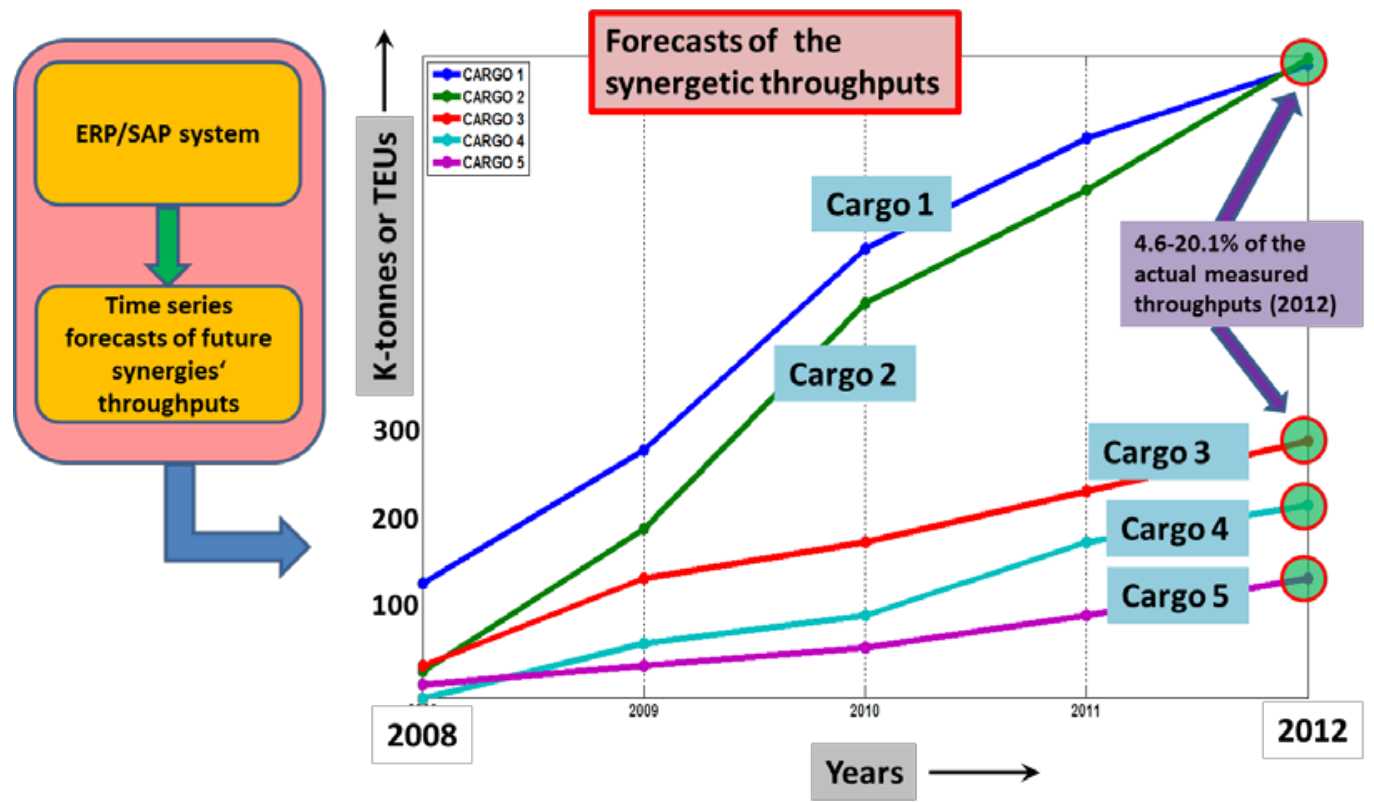

Figure 3. Predicted time-dependent synergetic throughputs $\hat{y}_{i t}=\hat{y}_{i}(t), i=1,2,3,4,5$ ( $\mathrm{i}$ - a type of cargo; measured in TEUs (containers) or in k-tones (other cargo)).

\section{CONCEPTUAL FRAMEWORK, MONTE CARLO ALGORITHM, AND APPUED VARIABLES}

\section{A. Conceptual Framework}

Fig. 4 shows a conceptual Monte Carlo framework with an integrated DCF model. Since a randomness is employed to some of the independent variables, the dependent ones take a random character as well. The DCF model surrounds the block $A$ for calculation of future synergetic cash flows denoted by $\hat{F} C F_{i t}(j)=\hat{F} C F_{i}(j, t), j=1, \ldots, M$ and the block $\mathrm{B}$ for calculation of present values of future synergies denoted by $\hat{P} V_{i j}, i=1,2,3,4,5, j=1, \ldots, M$. Here, index $\mathrm{j}$ refers to $\mathrm{MC}$ iterations, where $M$ is the total number of $M C$ simulations, while index i refers to a cargo type, and $t \in\{2008, \ldots, 2012\}$. The block A needs certain controlled financial parameters (i.e. revenue per cargo ton and EBITDA marg $i^{2}$ ) for its calculations, where the parameters' predefined uncerta inties are incorporated with random generators. The block $A$ also needs predicted synergetic forecasts $\hat{y}_{i t}=\hat{y}_{i}(t), i=1,2,3,4,5$, to which additional uncertainties are additionally injected by a multip lic a tive correction to take into account possible signific ant forec asting emrors. Moreover, while the block $A$ is executing derivations of synergetic cash flows, a nother correction of additive type is added to take into account possible errors related to the assumptions of DCF methodology. When block A completes the calculation of future cash flows, the computation of $\hat{P} V_{i j}, i=1,2,3,4,5, j=1, \ldots, M$ becomes possible on the basis of $\hat{F} C F_{i}(j, t)$, and financial parameters $\mathrm{g}$ (perpetuity growth rate), and WAAC, respectively. The latter is not controlled by us but is derived from the other financial parameters. The calculations just described are computed for each cargo type and for all iterations of MC procedure. At each iteration, the values of random generators that control all uncertainties in the process via predefined probability distributions, a re also changed to incorporate a new level of randomness. When the procedure is finished, an entire set of calc ulated present values of future synergies is created for each cargo type. Afterward, it is possible to apply a further statistical analysis to estimate the probability intervals and the likelihood of success of

\footnotetext{
${ }^{2}$ EBITDA - Earnings Before Interest, Taxes, Depreciation and Amortization.
} 
synergetic effects regarding individual cargo types. Moreover, the likelihood of success of total future synergetic effects comprised of all cargo types can also be estimated as a final result.

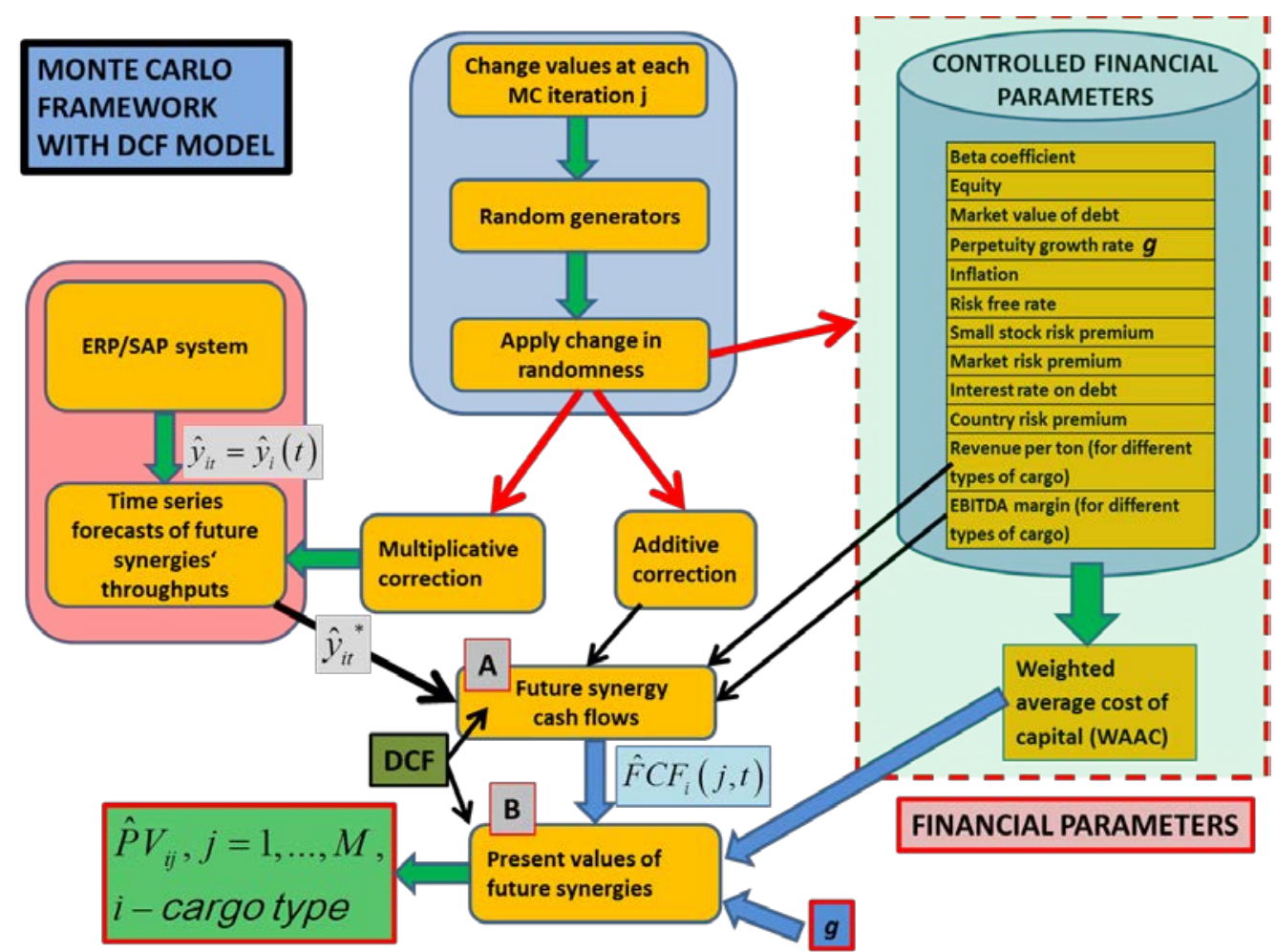

Figure 4. The conceptual Monte Carlo framework with an integrated DCF model.

\section{B. Applied Random Variables and Parameters}

Table 2 shows a description and statistical properties of all parameters and variables that are involved in the estimation of future synergetic effects by the means of DCF model and MC simulation. We can see that we are dealing with a quite big number of different variables and parameters. The precise meaning of applied financial parameters will become clearer later in this paper. As can be seen from Table 2, random generators with a normal probability distribution $N\left(\mu_{\text {param }}, \sigma_{\text {param }}\right)$ have been assigned to the majority of controlled financial parameters, which are independent (input) random variables in this case. Here, $\mu_{\text {param }}$ denotes a predefined mean value of the parameters, while $\sigma_{\text {param }}$ refers to their standard deviation. While setting $\mu_{\text {param }}$ and $\sigma_{\text {param }}$, the recommended values from the relevant literature have been used.

From Table 2 can also be seen that we assume nomal distributions for dependent (output) random variables, which are: 1 . An uncontrolled financial parameter. WAAC $($ waac $(j)) ; 2$. Estimated present values of future cash flows: $\hat{P} V_{i j}, i=1,2,3,4,5$; and 3 . Total present value of future cash flows: $\hat{P} V_{\text {alj }}=\sum_{i=1}^{5} \hat{P} V_{i j}$. Naturally, these nomality assumptions can not be confimed before an execution of MC algorithm. However, as it tums out, the further statistical analysis applied after finishing MC procedure discovers that histograms of dependent random variables indeed follow an approximately nomal distribution.

Table 2. A description and statistic al properties of all pa rameters and va ria bles that a re involved in the estimation of future synergetic effects via DCF and MC.

\begin{tabular}{|c|c|c|c|}
\hline $\begin{array}{c}\text { Random } \\
\text { Variable/Parameter }\end{array}$ & Meaning & $\begin{array}{c}\text { Applied/Derived Probability } \\
\text { Distribution }\end{array}$ & $\begin{array}{c}\text { Type of Random } \\
\text { Variable/Parameter }\end{array}$ \\
\hline
\end{tabular}




\section{Log istics \& Susta ina ble Tra nsp ort \\ Vol. 8, No. 1, Ma y 2017, 1-18 \\ doi: 10.1515/jlst-2017-0001}

\begin{tabular}{|c|c|c|c|}
\hline$\beta(j)$ & Beta coefficient & $N\left(\mu_{\beta}, \sigma_{\beta}\right)-$ normal & $\begin{array}{l}\text { Financial Controlled } \\
\text { random parameter }\end{array}$ \\
\hline$E(j)$ & Equity & $N\left(\mu_{E}, \sigma_{E}\right)$ & $\begin{array}{l}\text { Financial controlled } \\
\text { random parameter }\end{array}$ \\
\hline$D(j)$ & Market value of debt & $N\left(\mu_{D}, \sigma_{D}\right)$ & $\begin{array}{l}\text { Financial controlled } \\
\text { random parameter }\end{array}$ \\
\hline$g(j)$ & Perpetuity growth rate & $N\left(\mu_{g}, \sigma_{g}\right)$ & $\begin{array}{l}\text { Financial controlled } \\
\text { random parameter }\end{array}$ \\
\hline$I(j)$ & Inflation & $N\left(\mu_{I}, \sigma_{I}\right)$ & $\begin{array}{l}\text { Financial controlled } \\
\text { random parameter }\end{array}$ \\
\hline$r f r(j)$ & Risk free rate & $N\left(\mu_{r f r}, \sigma_{r f r}\right)$ & $\begin{array}{l}\text { Financial controlled } \\
\text { random parameter }\end{array}$ \\
\hline $\operatorname{ssrp}(j)$ & Small stock risk premium & $N\left(\mu_{\text {ssrp }}, \sigma_{\text {ssrp }}\right)$ & $\begin{array}{l}\text { Financial controlled } \\
\text { random parameter }\end{array}$ \\
\hline $\operatorname{mrp}(j)$ & Market risk premium & $N\left(\mu_{m r p}, \sigma_{m r p}\right)$ & $\begin{array}{l}\text { Financial controlled } \\
\text { random parameter }\end{array}$ \\
\hline $\operatorname{ird}(j)$ & Interest rate on debt & $N\left(\mu_{i r d}, \sigma_{i r d}\right)$ & $\begin{array}{l}\text { Financial controlled } \\
\text { random parameter }\end{array}$ \\
\hline$i r_{-} p c(j)$ & $\begin{array}{l}\text { Specific risk due to } \\
\text { synergies with partner } \\
\text { company }\end{array}$ & $N\left(\mu_{i r_{-} p c}, \sigma_{i r_{-} p c}\right)$ & $\begin{array}{l}\text { Financial controlled } \\
\text { random parameter }\end{array}$ \\
\hline $\operatorname{crp}(j)$ & Country risk premium & $N\left(\mu_{c r p}, \sigma_{c r p}\right)$ & $\begin{array}{l}\text { Financial controlled } \\
\text { random parameter }\end{array}$ \\
\hline $\begin{array}{l}\text { yrevpt }_{i j}, \\
i=1,2,3,4,5\end{array}$ & $\begin{array}{l}\text { Revenue per ton for Port } \\
\text { (i - type of cargo) }\end{array}$ & $N\left(\mu_{\text {yrevpt }_{i j}}, \sigma_{\text {yrevpt }_{i j}}\right)$ & $\begin{array}{l}\text { Financial controlled } \\
\text { random parameter }\end{array}$ \\
\hline $\begin{array}{l}\text { yebitda_m } m_{i j} \\
i=1,2,3,4,5\end{array}$ & $\begin{array}{l}\text { EBITDA margin for Port (i } \\
\text { - type of cargo) }\end{array}$ & $N\left(\mu_{\text {yebitda_m } m_{i j}}, \sigma_{\text {yebitda_}} m_{i j}\right)$ & $\begin{array}{l}\text { Financial controlled } \\
\text { random parameter }\end{array}$ \\
\hline $\operatorname{waac}(j)$ & $\begin{array}{l}\text { Weighted average cost of } \\
\text { capital }\end{array}$ & $\begin{array}{c}\text { Assumed normal after scenario } \\
\text { playing for } j=1, \ldots, M: \\
N\left(\mu_{\text {waac }}, \sigma_{\text {waac }}\right)\end{array}$ & $\begin{array}{l}\text { Financial uncontrolled } \\
\text { random parameter }\end{array}$ \\
\hline$\hat{F} C F_{i t}(j)$ & $\begin{array}{l}\text { Estimated Future synergy } \\
\text { cash flow dependent on } \\
\text { time ( } \mathrm{i} \text { - type of cargo) }\end{array}$ & & $\begin{array}{l}\text { Financial Random } \\
\text { variables }\end{array}$ \\
\hline$\hat{y}_{i t}, i=1,2,3,4,5$ & $\begin{array}{l}\text { Predicted Time- } \\
\text { dependent Synergy } \\
\text { Throughput ( } \mathrm{i} \text { - type of } \\
\text { cargo) }\end{array}$ & & $\begin{array}{l}\text { Throughput Predicted } \\
\text { variables }\end{array}$ \\
\hline$\hat{P} V_{i j}, i=1,2,3,4,5$ & $\begin{array}{l}\text { Estimated Present value } \\
\text { of future cash flow based } \\
\text { on synergies and type of } \\
\text { cargo }\end{array}$ & $\begin{array}{l}\text { Assumed normal after scenario } \\
\quad \text { playing for } j=1, \ldots, M \text { : } \\
N\left(\mu_{\hat{P} V_{i j}}, \sigma_{\hat{P} V_{i j}}\right)\end{array}$ & $\begin{array}{l}\text { Financial Random } \\
\text { variables }\end{array}$ \\
\hline$\hat{P} V_{a l l j}=\sum_{i=1}^{5} \hat{P} V_{i j}$ & $\begin{array}{l}\text { Estimated Total Present } \\
\text { value of future cash flow } \\
\text { based on synergies }\end{array}$ & $\begin{array}{l}\text { Assumed normal after scenario } \\
\quad \text { playing for } j=1, \ldots, M: \\
N\left(\mu_{\hat{P} V_{\text {allj }}}, \sigma_{\hat{P} V_{\text {all }}}\right)\end{array}$ & Financial Random variable \\
\hline$\hat{W} C_{i t}$ & $\begin{array}{l}\text { Estimated time- } \\
\text { dependent future } \\
\text { Working capital } \\
\text { investments ( } i \text { - type of } \\
\text { cargo) }\end{array}$ & & $\begin{array}{l}\text { Financial Predicted } \\
\text { variables }\end{array}$ \\
\hline
\end{tabular}




\section{Logistics \& Susta ina ble Tra nsport \\ Vol. 8, No. 1, May 2017, 1-18 \\ doi: 10.1515/jlst-2017-0001}

\begin{tabular}{|c|c|c|c|}
\hline$M$ & $\begin{array}{l}\text { Number of Monte Carlo } \\
\text { simulations (scenarios) }\end{array}$ & & Fixed predefined value \\
\hline$y_{\text {cor_ } i j}, i=1,2,3,4,5$ & $\begin{array}{l}\text { Multiplicative Correction } \\
\text { of } \hat{y}_{i t}, i=1,2,3,4,5\end{array}$ & $\begin{array}{c}U\left(a_{\text {corr } 1 i}, b_{\text {corr1i }}\right) \\
\text { (uniform) }\end{array}$ & $\begin{array}{l}\text { Statistical Controlled } \\
\text { random parameters }\end{array}$ \\
\hline $\begin{array}{l}F C F_{\text {cor_it }_{-}}(j), \\
i=1,2,3,4,5\end{array}$ & $\begin{array}{l}\text { Time dependent Additive } \\
\text { Correction of } \\
\hat{F} C F_{i t}(j)\end{array}$ & $N\left(\mu_{\text {corr } 2 i}, \sigma_{\text {corr } 2 i}\right)$ & $\begin{array}{l}\text { Statistical Controlled } \\
\text { random parameters }\end{array}$ \\
\hline$i=\left\{\begin{array}{l}1-c \arg o 1 \\
2-c \arg o 2 \\
3-c \arg o 3 \\
4-c \arg o 4 \\
5-c \arg o 5\end{array}\right.$ & Types of cargo & & \\
\hline
\end{tabular}

\section{Working mechanism of Monte Carlo Algorithm with DCF model}

On the basis of Fig. 4, Figure 5 can be applied showing further details of a working mechanism of conducted Monte Carlo algorithm with integrated DCF model. The latter was developed by the means of program package Matlab. After completed reading of initial data (block $A$ ) and setup of random generators (block B), the $M C$ algorithm starts with generating different possible scenarios for future synergetic effects. At each j-th iteration, random generators provide different random values to corresponding controlled financial parameters (block $C$ ). These are then used for a new calc ulation of future cash flows and corresponding values of future synergies by using a DCF model (block D). Further, the achieved results are saved (block E), while the procedure continues with a new, $j+1$-th iteration. When the algorithm is totally completed after executing $M$ scenarios, the distributions of values of predicted future synergies are also obtained in the form of histograms (block F). Fina lly, the tests of noma lity a re a pplied for dependent random variables (block $G$ ), while a subsequent statistical a na lysis can also be further proceeded. 


\section{Log istics \& Susta ina ble Tra nsp ort \\ Vol. 8, No. 1, May 2017, 1-18 \\ doi: 10.1515/jlst-2017-0001}

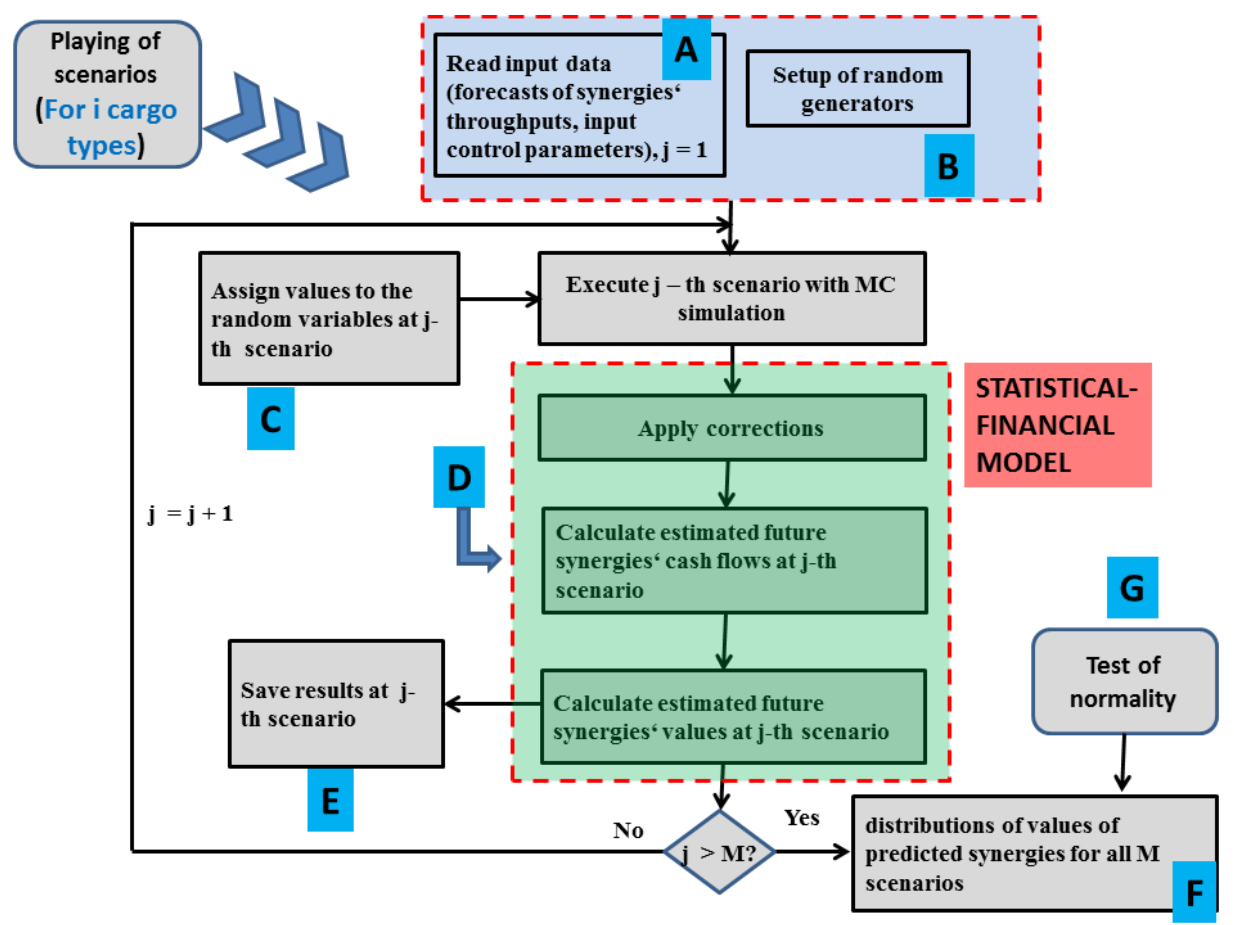

Figure 5. Further details of a working mechanism of conducted Monte Ca rlo algorithm with integrated DCF model (programmed in Matlab)

Even clearer picture of the main idea behind an analysis of synergetic effects based on Monte Carlo scenario playing is illustrated in Fig. 6.



Figure 6: The main idea behind an analysis of synergetic effects based on Monte Carlo scenario playing 
As afore-mentioned, the DCF method values certa in asset or resource (synergy in our case) on the basis of the present value (PV) of its estimated future cash flows which should be discounted by a suitable discount rate $r_{j}$. According to literature about corporate finance (for instance [14, 17, 18], etc.), the formula for calculating the PV of various future cash flows can be applied by the following approximate structure:

$$
\begin{aligned}
& \hat{P} V_{i j}=\hat{P} V_{i j p e r i o d 1}+\hat{P} V_{i j p e r i o d}=\sum_{t=1}^{n} \frac{\hat{F} C F_{i j}(t)}{\left(1+r_{j}\right)^{t}}+\sum_{t=n+1}^{\infty} \frac{\hat{F} C F_{i j}(t)}{\left(1+r_{j}\right)^{t}}= \\
& \approx \sum_{t=1}^{n} \frac{\hat{F} C F_{i j}(t)}{\left(1+r_{j}\right)^{t}}+\frac{T V_{i j}(n)}{\left(1+r_{j}\right)^{n}} \approx \sum_{t=1}^{n} \frac{\hat{F} C F_{i j}(t)}{\left(1+r_{j}\right)^{t}}+\frac{\hat{F} C F_{i j}(n) \cdot\left(1+g_{j}\right)}{\left(r_{j}-g_{j}\right)} \cdot \frac{1}{\left(1+r_{j}\right)^{n}}
\end{aligned}
$$

where indexes $\mathrm{i}$ and $\mathrm{j}$ have the same meaning as in previous sections. Here, the $T V_{i j}(n)$ represents the teminal value, observed at a teminal yearafter the end of projection period. Teminal value is a value of all future cash flows that are accumulated in the future after the end of observed time period $t \in\{0, \ldots, n\} \Rightarrow t \in\{2008, \ldots, 2012\}[14,39,40]$. For the calculation of $T V_{i j}(n)$, an Advanced Perpetuity Gord on Growth Model has been conducted [17, 39,40]. This model represents a part of the value of future cash flows that continue growing at an assumed constant growth rate in perpetuity. Predicted future cash flows can be expressed as a function of multiplic a tively corrected predicted synergetic forecasts $\hat{y}_{i j t}{ }^{*}$, revenues per cargo ton $y r e v p t_{i j}$, EBITDA margins for each cargo type yebitda_ $m_{i j}$, and additive corrections of cash flows $F C F_{c o r} i j t$ :

$$
\begin{aligned}
& \hat{F C F} F_{i j}(t)=f_{1}\left(\hat{y}_{i j t}{ }^{*}, \text { yrevpt }_{i j}, \text { yebitda }_{-} m_{i j}, F C F_{\text {cor_ijt }}\right) \\
& i=1, \ldots, 5, j=1, \ldots, M
\end{aligned}
$$

Here, multiplicatively corrected predicted synergetic forecasts $\hat{y}_{i j t}{ }^{*}$ can be expressed as a function of predicted synergetic forecasts $\hat{y}_{i t}$ and corresponding multiplic ative corrections $y_{\text {cor }-i j}$ :

$$
\hat{y}_{i j t}^{*}=f_{2}\left(\hat{y}_{i t}, y_{\text {cor_ij }}\right), i=1, \ldots, 5, j=1, \ldots, M
$$

There exist several concepts, how to choose a suitable discount rate $r_{j}$. In a case of valuation of investments and other invisible resources (e.g. synergies), the discount rate is often chosen as: $r_{j}=\operatorname{waac}(j)$, so we can use a weighted average cost of capital. The WAAC represents the rate that a firm is anticipated to pay on average to all its security holders to finance firm's assets. Accordingly, the WACC refers to the minimum retum that a firm must eam on an existing asset base to satisfy its owners, creditors, and other suppliers of capital, otherwise they will invest elsewhere [17, 22]. The WACC is derived by weighting the sources of capital with respect to the fim's financial structure and afterward multiplying them with their costs. Accordingly, the Formula for the WACC derivation is $[17,18,22]$ :

$$
\begin{aligned}
& r(j)=\operatorname{waac}(j)=\frac{D(j)}{D(j)+E(j)} \cdot K_{d}(j)+\frac{E(j)}{D(j)+E(j)} \cdot K_{e}(j) \\
& \text { where } \\
& K_{d}(j)=(1-\operatorname{tax}) \cdot \operatorname{ird}(j) ; \quad K_{e}(j)=f_{3}[r f r(j), \beta(j), \operatorname{mrp}(j), \operatorname{ssrp}(j), \operatorname{crp}(j)]
\end{aligned}
$$

Here, $K_{d}$ is a cost of debt, $K_{e}$ is a cost of equity, $\frac{E}{D+E}$ is a portion of equity in financing resources, while $\frac{D}{D+E}$ is a portion of debt in the financing resources. The cost of equity can be 
calculated in several different ways depending on fim's characteristics. Nevertheless, the so-called capital asset pricing model (CAPM) is in general always involved in the calculation of $K_{e}[17,18$, 22]. The CAPM model defines the relationship between risk and expected retum and reflects the fact that investors need to be rewarded in the sense of two important factors: time value of money and risk.

The first factor is characterized by the risk-free rate $\operatorname{rfr}(j)$ and rewards the financiers for placing money in any investment over a certa in period of time. The second factor represents the a mount of compensation the financier needs for taking on additional risk. It is calc ulated by the means of a risk measure $\beta(j)$ and the market risk premium $\operatorname{mrp}(j)$ and usually takes the form: $\beta(j) \cdot[\operatorname{mrp}(j)-r f r(j)]$. Moreover, in certain specific cases, the parameters $\operatorname{ssrp}(j), \operatorname{crp}(j)$ must also be conducted in the calculation of $K_{e}[17,18,22]$.

\section{PRAC TIC AL NUMERIC AL RESULTS}

\section{A. Distribution of predicted present values of future synergies for different types of ca rgo}

Fig. 7 shows the distributions of estimated values of synergies $H\left(\hat{P} V_{i j}\right), i=1,2,3,4,5, j=1, \ldots, M$ for different types of cargo in terms of calculated histograms, which were generated during the Monte Carlo procedure and analyzed afterward. Despite the fact that an experiment was repeated for different total numbers of simulations $M$, the $M C$ algorithm has always a chieved quite similar results in a statistical sense. As can be seen from Fig. 7, the continuous probability density function representing the nomal distribution is also added for the purpose of comparison with the calcula ted histograms. This comparison is possible since the statistic al tests for no mality (i.e. J a rqueBerra J B test and Lilliefors test [41]), as well as desc riptive sta tistics (i.e. skewness index Sl and kurtosis index $\mathrm{KI}$ ) have confimed that all histograms more or less follow an approximately nomal distribution. Moreover, the statistical analysis has also shown that a histogram for waac $(j)$ follows approximately the nomal distribution as well.

As can be noticed from Fig. 7, the lower and upper bounds of distributions, which are: $\left(\hat{P} V_{i L}=X_{i L}\right.$ mil EUR, $\hat{P} V_{i U}=X_{i U}$ mil EUR $) \in \overline{\hat{P} V_{i j}} \pm 1.96 \cdot \sigma_{\hat{P} V_{i j}}$, have also been added for each cargo type (see the left and right big circle). Since we are dealing with approximate nomal distributions, we can roughly imply the following statement: The probability that a future value of the synergy $\hat{P} V_{i j}=X_{i j}$ mil EUR will fall into the interval $\left(\hat{P} V_{i L}=X_{i L}\right.$ mil EUR, $\left.\hat{P} V_{i U}=X_{i U} m i l E U R\right) \in \overline{\hat{P} V_{i j}} \pm 1.96 \cdot \sigma_{\hat{P} V_{i j}}$, is equal $95 \%$ [41]. Mathematically we can express this with: $P\left(\hat{P} V_{i L} \leq \hat{P} V_{i j} \leq \hat{P} V_{i U}\right)=P\left(X_{i L} m i l \leq \hat{P} V_{i j} \leq X_{i U}\right.$ mil $)=95 \%$. The scenario in which a future value of the synergy $\hat{P} V_{i j}=X_{i j}$ mil EUR will take a value in the center of the aforementioned interval, that is $\left(\overline{\hat{P} V_{i j}}=\hat{P} V_{i M}=X_{i M}\right.$ mil ), is denoted with a middle big circle.

Further details about estimated results (i.e. actual numbers in terms of millions EUR due to different types of cargo) are not provided in this paper since they are not allowed to be public ally revealed. It can be only emphasized that the calculated $95 \%$ based probability intervals for the possible future synergies (see three big circles in Fig. 7!) have covered signific ant values in Mill EUR: $\left(X_{i L} m i l, X_{i U} m i l\right)>>0$. Despite we are not allowed to uncover how are the achieved synergetic values distributed among the different cargo types, we can still provide some partial information to ensure an easier understanding to the reader, as follows (c.f. Fig. 7): 


\section{Logistic \& \& Susta ina ble Tra nsp ort \\ Vol. 8, No. 1, May 2017, 1-18 \\ doi: 10.1515/jlst-2017-0001}

$$
\begin{aligned}
& X_{1 L}=4.1 \mathrm{mil} \mathrm{EUR} ; \quad X_{1 M}=11.35 \mathrm{mil} \mathrm{EUR} ; X_{1 U}=18.6 \mathrm{mil} \mathrm{EUR} \\
& X_{2 L}=1.3 \text { mil EUR; } X_{2 M}=4.1 \mathrm{mil} \mathrm{EUR;} X_{2 U}=6.9 \mathrm{mil} \text { EUR } \\
& X_{3 L}=1.1 \mathrm{mil} \mathrm{EUR;} \quad X_{3 M}=3.55 \mathrm{mil} \mathrm{EUR} ; X_{3 U}=6.0 \mathrm{mil} \mathrm{EUR} \\
& X_{4 L}=1.6 \text { mil EUR; } X_{4 M}=4.1 \mathrm{mil} \mathrm{EUR;} X_{4 U}=6.8 \mathrm{mil} \mathrm{EUR} \\
& X_{5 L}=0.3 \text { mil EUR; } X_{5 M}=1.15 \text { mil EUR; } X_{5 U}=2.2 \text { mil EUR }
\end{aligned}
$$

The results just given confirmed that we have proved that the likelihood of appearance of substantial future synergies is quite big. Accordingly, it can also be expected that the collaboration between both companies will indeed signific antly raise the level of cargo throughputs. Thus, the port can expect signific ant synergetic based benefits in terms of considerable values in millions EUR in the future, which justifies the decision about establishing a strategic partnership with the logistic company.
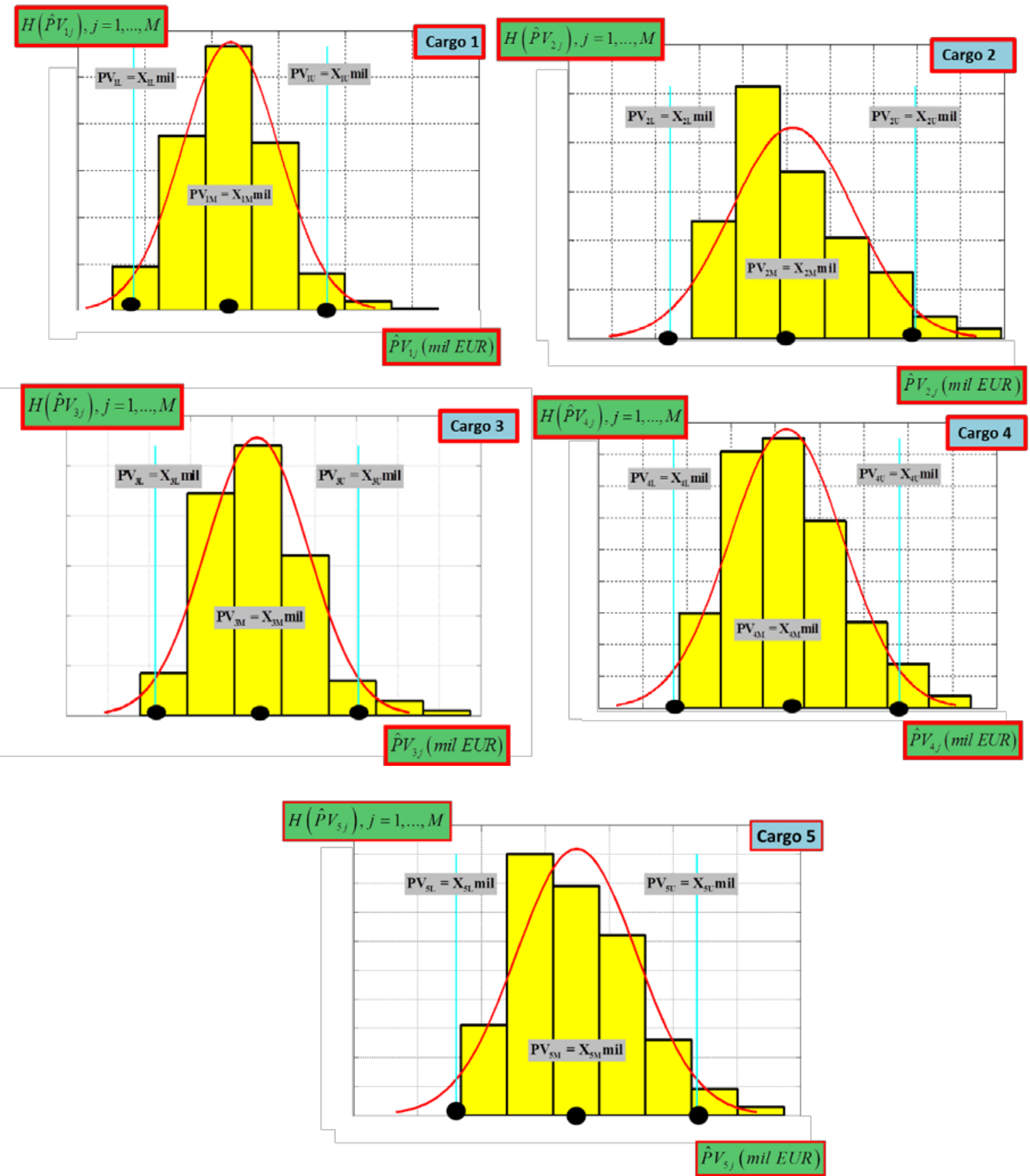
Figure 7. The distributions of estimated synergetic values $H\left(\hat{P} V_{i j}\right), i=1,2,3,4,5, j=1, \ldots, M$ for different cargos ( $X$ axis: PV of future cash flows in mil EUR; y axis: Frequency distribution - as a histogra $m$ ).

B. Distribution of predic ted present values of future synergies for total cargo

Fig. 8 shows the distribution of estimated values of future synergies $H\left(\hat{P} V_{\text {allj }}\right)=H\left(\sum_{i=1: 5} \hat{P} V_{i j}\right), j=1, \ldots, M$ for a total cargo in terms of a calculated histogram. The latter is based on the values of the total future synergies, which were obtained by using a summation of partial synergetic values of individual cargos calculated at each MC iteration. The findings are similar as in the previous section a ddressing different types of cargo. In Fig. 8 we have added, as in the previous section, the continuous probability density function for the normal distribution. The comparison between the latter and the obtained histogram is possible since the statistical tests for noma lity (J B test, Lilliefors test) and a descriptive statistics ( $\mathrm{SI}$ and $\mathrm{KI}$ ) have confimed the existence of an approxima tely nomal distribution once again, this time for the histogram $H\left(\hat{P} V_{\text {allj }}\right)$.

Similarly as before, the lower and upper bounds of a corresponding distribution, which are: $\left(\hat{P} V_{\text {allL }}=X_{\text {all }}\right.$ mil EUR, $\hat{P} V_{\text {all }}=X_{\text {all }}$ mil EUR $) \in \overline{\hat{P} V_{\text {all }}} \pm 1.96 \cdot \sigma_{\hat{P} V_{\text {allj }}}$, have also been added in Fig. 8 (see the left and right big circle), with a center of the interval $\overline{\hat{P} V_{\text {allj }}}=P V_{\text {allM }}=X_{\text {allM }}$ mil (middle big circle). Once more, we can roughly imply the following statement: The probability that a future value of the total synergy $\hat{P} V_{a l j}=X_{\text {alj }}$ mil EUR (joint synergetic value for all cargo types) will fall into

the interval $\quad\left(\hat{P} V_{\text {all }}=X_{\text {allL }}\right.$ mil EUR, $\hat{P} V_{\text {all }}=X_{\text {all }}$ mil EUR $) \in \overline{\hat{P} V_{\text {allj }}} \pm 1.96 \cdot \sigma_{\hat{P} V_{\text {alli }}}$, is equal $95 \%$. Or, mathematic ally expressed: $P\left(\hat{P} V_{\text {all }} \leq \hat{P} V_{\text {allj }} \leq \hat{P} V_{\text {allu }}\right)=P\left(X_{\text {all }}\right.$ mil $\leq \hat{P} V_{\text {all }} \leq X_{\text {allu }}$ mil $)=95 \%$.

Similarly, as before, the further details about estimated results (i.e. actual numbers in terms of millions EUR) a re not provided here since they are not allowed to be public ally revealed. We can only emphasize that it happens again that the calculated $95 \%$ based probability interval for the possible future total synergies (see three big circles in Fig. 8!) covers significant values in Mill EUR: $\left(X_{\text {all }}\right.$ mil, $X_{\text {all }}$ mil $)>>0$. Nevertheless, just as a hint, we can roughly deduce about true achieved synergetic values by observing the partial results for each cargo type (see expressions (5)). 




Figure 8 . The distribution of estimated values of total future synergies

$$
H\left(\hat{P} V_{\text {allj }}\right)=H\left(\sum_{i=1: 5} \hat{P} V_{i j}\right), j=1, \ldots, M \text { (for a total c argo - all cargo types); } x \text { axis - PV in mil EUR. }
$$

Similarly, as in the previous chapter, we are very limited to enable the reader to estimate the true dimensions of the achieved synergies. We can only tell that the latter roughly reach about $7.5 \%-23 \%$ (depending on the scenario likelihood) of the operating revenue of the port in 2012 . To summarize, we have also proven in this case that the likelihood of appearance of substantial total future synergies is quite big. This fact can be considered as the most important finding of our paper. Moreover, it provides a final confimation about the appropriateness of a port's management decision to establish a strategic alliance with a logistic company. Namely, on the basis of this research, we can disc uss about a big chance of a significant increase in the level of the future cargo throughputs. Hence, the port can expect significant additional revenue in the future that will occur as a consequence of synergetic effects a risen on the basis of a synchronized and efficient coordination of both companies.

\section{CONCLUSION}

The paper addressed an analysis of potential synergies in a strategic collaboration between the observed port and a logistic company, which provides railway services as its primary activity. The main motive for such strategic alliance was cooperation on the basis of joint benefits related to a rail freight transport. When a relationship was established, it was expected that a synchronized optimal coordination of mutual activities would also increase the cargo throughput volume in the port. One of the main reasons for such kind of sumplus in cargo amount was supposed to be an appearance of significant synergetic effects that would arise in the strategic collaboration between both companies.

For the purpose of synergies valuation, a discounted cash flow model integrated into the Monte Carlo simulation-based framework was applied. The DCF model obtained for each cargo type needed the predicted future synergetic throughputs, which were acquired by the means of the port's ERP/SAP system. The DCF model a lso contained several uncerta in financial parameters that have been treated as random variables following specific predefined probability distributions. When a MC process was finished, we have obtained a large number of generated synergies' values. As it tumed out, these values have followed an approximately nomal distribution regardless of cargo type. Moreover, the total synergies' values followed a nomal distribution as well. 
In the next step of our research, statistical inference and analysis of probability intervals from calculated histograms were conduc ted. The statistic al a nalysis ha s shown that there ind eed exists a high probability of appearance of substantial future synergetic values for all cargo types of the observed port. More importantly, due to an estimated high probability of the existence of significant total future synergies, this fact represents an important indic a tor a bout the usefulness of collaboration between both companies.

Accordingly, our findings result in the important conclusion that the judgment about establishing a strategic alliance with the logistic company was an adequate decision of the port's management. Besides this important find ing, we believe that another contribution of this paper is a demonstration how the Monte-Carlo method combined with the DCF model can be efficiently used to calculate synergies initiating an extra surplus of the port's cargo throughput. Moreover, there have been practically no studies detected in the literature that would investigate the synergetic effects based on strategic alliances between the ports and logistic companies within the scope of supply chain management.

In the future work, it is planned to conduct some other financial models for a valuation of synergies that arise in collaboration between the observed port and logistic company. Furthemore, it is also intended to apply other kinds of probability distributions for incorporating unc ertainties in the financial parameters of the valuation models.

\section{AUTHORS}

A. Dejan Dragan, Phd, is Asso c iate Professor at the Fac ulty of Log istic s, University of Maribor, Celje, Slovenia (e-mail: dejan.dragan@um.si).

B. Bojan Rosi, Phd, is Full Professor and the Dean at the Faculty of Logistics, University of Maribor, Celje, Slovenia (e-mail: bojan.rosi@um.si).

C. Toni Avžner, MSc, the President of the ALUMNI CLUB at the Faculty of Logistics, University of Maribor, Celje, Slovenia (e-mail: logic eto@gmail.com).

Manuscript received by 29 March 2017.

\section{REFERENCES}

[1] E. Todeva and D. Knoke, "Strategic a lliances and models of collaboration", Management Decision, vol. 43, no. 1, pp. 123-148, 2005.

[2] J. Czaja, "Examples of Suc cessful Strategic Alliances", Smallbusiness.chron.com, 2016. [Online]. Available: http://smallbusiness.chron.com/exa mples-suc c essful-stra tegic-allianc es-13859.html. [Acc essed: 21J un- 2016].

[3] N. Kovačić, D. Topolšek and D. Dragan, "Tourism sector, Travel agencies, and Transport Suppliers: Comparison of Different Estimators in the Structural Equation Modeling", Logistics \& Sustainable Transport, vol. 6, pp. 11-24, 2015.

[4] G. Beneke, W. Schurink, and G. Roodt, "Towards a substantive theory of synergy", SA J oumal of Human Resource Management, vol. 5, pp. 9-19, 2007.

[5] A. Damodaran, Investment valuation, 2nd ed., New York: Wiley, 2002.

[6] A. Damodaran, The Value of Synergy, New York: Stem Sc hool of Business, 2005.

[7] V. Dragota and I. M. Dragota, "Models and indic ators for risk valuation of direct investments", Economic computation and economic cybemetic s studies and research, 43(3), 69-75, 2009.

[8] C. P. Schumann, "Improving Certainty in Valuations using the Discounted Cash Flow Method", Valuation Strategies Magazine, vol. 10, pp. 4-13, 2006.

[9] G. Pfefer and U. Kusiatin, "The Path to Strategic Manufacturing Flexibility", 2Value Consulting Group Inc. (C)

[10] M. J effery, "Retum on Investment Ana lysis for E-business Projects", The Intemet Encyclopedia. J ohn Wiley \& Sons, Inc., 2004. 
[11] W. Knull, S. J ones, T. Tyler and R. Deutsch, "Accounting for Uncertainty in Discounted Cash Flow Valuation of Upstream Oil and Gas Investments", J oumal of Energy \& Natural Resources Law, vol. 25, no. 3, pp. 268-302, 2007.

[12] S. Lifland, "Creating a Dynamic DCF Analysis: A Detailed Excel Approach Utilizing Monte Carlo Methodology", J oumal of Higher Education Theory and Practice, vol. 15, no.2, pp. 56-66, 2015.

[13] S. J ayaraman, "A Review of Monte Carlo Methods in Real Estate", State University, Florida, 2013.

[14] F. Steiger, The Validity of Company Valuation Using Discounted Cash Flow Methods, European Business School, 2016.

[15] M. A. Mehari and J. R. Tumer, A Monte Carlo comparison between the free cash flow and discounted cash flow approaches, Tinbergen Institute Rotterdam, 2002.

[16] M. Yang, "Modeling Investment Risks and Uncerta inties with Real Options Approach", Intemational Energy Agency Working Paper Series, vol. 13, pp. 1120-1137, 2007.

[17] T. Copeland and J. Weston, Financial theory and corporate polic y. Reading, Mass.: Addison-Wesley, 1988.

[18] A. Damodaran, Corporate finance: theory and practice, 2nd ed., New York: Wiley, 2001.

[19] H. I. Ansoff, Corporate Strategy: an Analytic Approach to Business Policy for Growth and Expansion, New York: MacGraw-Hill, 1965.

[20] A. De Graaf, "Qua ntifying Synergy Value In Mergers And Acquisition", Msc, University Of South Africa, 2010.

[21] S. Chatterjee, "Types of synergy and economic value: The impact of acquisitions on merging and rival firms", Strat. Mgmt. J ., vol. 7, no. 2, pp. 119-139, 1986.

[22] T. Koller, M. Goedhart and D. Wessels Valuation - measuring and managing the value of companies, New J ersey: J ohn Wiley \& Sons, 2005.

[23] R. G. Eccles, K. L. Lanes and T. C. Wilson, "Are You Paying Too Much for That Acquisition?", Harvard Business Review, vol. 77, pp. 136-146, 1999.

[24] S. Knoll, C ross-business synergies. Wiesbaden: T. Gabler, 2008.

[25] H. E. Johnson, "Placing a Value on Synergies and Strategic Advantage," Campbell Valuation Partners Limited Toronto, 2002.

[26] S. Loomer, C. A. Cbv, and A. Harington, "Sharing Synergies", Duff \& Phelps, 2014. [Online]. Available: http:// www.d uffand phelps.com/insights/public a tions/index. [Acc essed: 25- J un- 2016].

[27] L Miles, A. Borchert and A. E. Ramanathan, "Why Some Merging Companies Become Synergy Overachievers", Bain\&Company, $2014 . \quad$ [Online]. Available: http :// www.bain.com/public ations/artic les/ why-some-merging-companies-become-synergyoverachievers.aspx. [Accessed: 24- J un- 2016].

[28] J . A. Weber and U. M. Dholakia, "Including Marketing Synergy in Ac quisition Analysis", Industrial Marketing Mana gement, vol. 29, pp. 157-177, 2000.

[29] F. David, Strategic management. Upper Sa ddle River, N.J .: Prentice Hall, 2011.

[30] G. Bemile and E. Lyandres, "Merger Synergies Along the Supply Cha in", European Winter Finance Summit, vol. 201, no. 1, 2011.

[31] A. Damodaran, Investment valuation. Hoboken, New J ersey: Wiley, 2012.

[32] A. Damodaran, "Valuation Approaches and Metrics: A Survey of the Theory and Evidence", Stem School of Business, pp. 1-77, 2006.

[33] J. Bergh and J. de Neergaard, "Valuing synergies", Bachelor thesis, University Of Gothenburg School Of Business, Ec onomics And Law, 2011.

[34] A. Damodaran, Applied corporate finance, New J ersey: J ohn Wiley \& Sons, 2010.

[35] S. P. Pratt, Valuing a Business: The Analysis and Appraisal of Closely Held Companies, 5th ed., England: McGraw-Hill, 2008.

[36] C. M. Mellen and F. C. Evans, Valuation for M\&A: Building Value in Private Companies, New York: John Wiley \& Sons, 2001.

[37] D. B. Hertz, "Risk a nalysis in capital investment", Harva rd Business Review, vol. 42, pp. 95-106, 1964.

[38] J . Akhtar, Production Planning and Control with SAP ERP. Bonn: Ga lileo Press, 2013.

[39] D. Laurentiu, "Determination Of Residual Value Within The Cost Benefit Analysis For The Projects Financed By The European Union", The Annals of the University of Oradea, vol. 1, pp. 354-360, 2011.

[40] B. C. Benninghoff, "Discounted Cash Flow Method", Users.wfu.edu, 1998. [Online]. Available: http:// users.wfu.edu/pa Imita r/ La w\&Valua tion/chapter 5/Documents/ Steiner-v-Benninghoff-fullc ase.html. [Ac cessed: 24 J un- 2016].

[41] B. Remillard, Statistical methods for financial engineering, Boca Raton, FL: CRC Press, 2013. 